\title{
Quality Assessment of Clay for Limestone Calcined Clay Cement Production
}

\author{
Aditya Singhal ${ }^{1}$ \\ ${ }^{1}$ M.Tech Scholar, Dept. of civil Engineering Pacific \\ Academy of Higher Education and Research University, \\ Udaipur, Rajasthan (India)
}

\begin{abstract}
Being the biggest material utilized by humanity after water, concrete and related businesses have grind sway on development and improvement of a nation. Despite the fact that generally modest, the way toward making its fixings produces $\mathrm{CO2}$. The significant offer for this natural issue from concrete is because of the creation of concrete which is a basic segment. Discharges from concrete creation are predominantly because of development of clinkers which are fundamentally concrete knobs which blend and crush with gypsum to deliver Ordinary Portland concrete $C$ (OPC). It requires the crude materials to be warmed at high temperature (up to $1500^{\circ}$ ) to create clinker. The synthetic procedure associated with clinkerization where the limestone changes into lime and $\mathrm{CO} 2$ is answerable for $50-75 \%$ of outflow. Utilization of electrical vitality required to pound the crude materials likewise contributes its offer. Because of the raising worry against the ozone harming substance discharges and a dangerous atmospheric deviation, ventures and nations are encouraged to see vital strides to check this worldwide issue. It is evaluated that concrete industry is liable for around $6-8 \%$ of worldwide $\mathrm{CO} 2$ outflow.
\end{abstract}

As it is the quickest developing economy and amongst the most populated nations on the planet, India is about to turn into the biggest shopper of concrete in not so distant future by surpassing China. Because of exponential consumption of value crude materials just as ecological issues from the customary OPC creation, it is critical to take a gander at substitute approaches to deliver the folio in India. The most well-known and broadly acknowledged technique is clinker substitution by strengthening cementitious materials (SCMs). As significant piece of the electrical vitality in the nation originates from coal based warm force plant, which produces fly debris, a SCM all in all; a great deal of examination has been done in the use of fly debris in concrete creation. As of now according to the Bureau of Indian Standard (BIS), 30-40\% of clinker can be supplanted with fly debris which meets the necessary quality standards. Despite the fact that, because of the absence of accessibility great quality fly debris and different government guidelines, the complete piece of the overall industry of fly debris based PPC in India, is around $65 \%$ as it were.

\author{
Pradyumna Dashora ${ }^{2}$ \\ ${ }^{2}$ Assistant Professor, Dept. of civil Engineering Pacific \\ Academy of Higher Education and Research \\ University,Udaipur, Rajasthan (India)
}

In late exploration in India, another inventive ternary mixed concrete, known as Limestone Calcined Clay Cement (Limestone Calcined Clay Cement) which can supplant clinker up to half by utilizing calcined mud and limestone, were created. Anticipating the significance of the new green innovation, an activity has taken to examine its attainability in India in primer examinations, it was discovered that the vital quality necessities can get in this new composite concrete, even with bad quality crude materials sub-par in which it contains contaminations.

Keywords:- global warming; innovative; technology; environment; conventional ; green house gas.

\section{INTRODUCTION}

For the creation of Limestone Calcined Clay Cement, following materials are required. Calcined kaolinitic mud limestone, gypsum and clinker. Clinker is generally accessible with concrete delivering units and can be brought off the rack. In spite of the fact that it differs between different organizations, choice can be founded on necessities. No adjustment in gypsum was visualized since compound gypsum was proposed to be utilized. For limestone, it was proposed to utilize a moderate to low $\mathrm{MgO}$ content material. The rest of the thing, mud which generally accessible in the world's covering and can without much of a stretch be dehydroxilated at temperatures extending between $750^{\circ} \mathrm{C}-800^{\circ} \mathrm{C}$ to create calcined earth. Calcined mud shows brilliant pozzolanic properties and is one of the significant crude materials of delivering Limestone Calcined Clay Cement. In the long run, the genuine extent of planning assets for Limestone Calcined Clay Cement combined for the most part into reasonable mud with kaolinitic content .

\section{APPROACH TO EVALUATION}

\section{$>$ Clay detail based on secondary literature}

Clay minerals are very common in fine grained sedimentary rocks such as shale, mudstone, and siltstone and in fine grained metamorphic slate and phyllite. Clay minerals include the following groups:

- Kaolin group which includes the minerals kaolinite, dickite, hallo site, and nacrite (polymorphs of $\mathrm{Al} 2 \mathrm{Si} 2 \mathrm{O} 5(\mathrm{OH}) 4)$. 


\section{A. Demarcate between commercial mines and prospected deposits}

Kaolin, otherwise called china dirt, is an unadulterated assortment of characteristic earth framed by enduring of feldspars. It is dominatingly comprises of Kaolinite (A12O3.2SiO2.2H2O),

Related with other earth minerals,Kaolin is industrially esteemed for its whiteness colour and fine molecule size which recognize it from different dirts. Other physical qualities that impact business requirement incorporate splendor, reflexivity, abrasiveness and thickness. Visit to commercial Mines:Gujrat and Rajasthan

\section{B. Visit to commercial Mines:Gujrat and Rajasthan}

China earth events in Gujarat and Rajasthan are frequently delicate and can undoubtedly be extricated without impacting. Earth and overburden are quarried in seats. In barely any mines, pieces of machinery and excavators are utilized to expel the overburden which is then shipped through truck/farm hauler/trailers and dumped at close by lands. Later removed mining zones are filled by these waste and overburden materials. All out hold of china dirt in Gujarat was 110 million tones in 2009-2010. In contrast to china earth, lime stone happens nearly in all stratigraphic skylines in Gujarat state. Absolute save of limestone in Gujarat was about 20010 million tons in 20092010 which was practically $10-12 \%$ of complete save in India.

\section{Analysis of samples deposits}

\begin{tabular}{|c|c|c|}
\hline District & \% Kaolinite & XRD analysis \\
\hline Bikaner & $\begin{array}{c}\text { High:50-60 } \\
\text { Low:40-50 }\end{array}$ & $\begin{array}{c}\text { Major: kaolinite, quartz } \\
\text { Minor:Muscovite, } \\
\text { clinochlore }\end{array}$ \\
Nagaur & $\begin{array}{c}\text { High:70-80 } \\
\text { Low:50-60 }\end{array}$ & $\begin{array}{c}\text { Major: kaolinite, quartz } \\
\text { Minor:Muscovite, } \\
\text { clinochlore }\end{array}$ \\
\hline
\end{tabular}

Table 1

\section{$>$ Processing}

Analysis for compositional deviation.

- Crushing, calcination, creation of concrete in ball factory.

\section{$>$ Analysis of concrete and mortar}

- Analysis of mortar and solid example.

It has likewise chosen to focus the zones/mines/tests for nitty gritty documentation dependent on the accompanying models.

- Origin of china mud - geography

- Physical appearance :Colour

- Mine criticism and business esteem

- Current scope of china mud and its geography

- Max hold of clay

- Commute through street, rail or ocean.

- Proximity of turning calcination office.

\section{METHOD AND METHODOLOGY ADOPTED}

Right off the bat Life cycle evaluation of OPC ,PPC and Limestone calcined dirt concrete was considered trailed by portrayal and testing

\section{Energy and Emission :Life Cycle Assessment of OPC,PPC and Lime Stone Calcined Clay Cement}

Life Cycle Assessment (LCA) is a strategy to evaluate ecological effects related with all the phases of an item's life. The current examination investigations three sorts of concretes for example Standard Portland Cement (OPC), Portland Pozzolana Cement (PPC) and Limestone Calcined Clay Cement (Limestone Calcined Clay Cement) for $\mathrm{CO} 2$ emanations and vitality utilization. This investigation is done from mining of every crude material to pressing of concrete. Basic role of the examination is to look at creation execution of OPC, PPC and Limestone Calcined Clay Cement as far as $\mathrm{CO} 2$ discharges and vitality utilization.

System follows ISO Standards 14040:2006 Principles and Framework and ISO Standards 14044:2006 Requirements and Guidelines. The three concrete sorts for example OPC, PPC and Limestone Calcined Clay Cement were surveyed for $\mathrm{CO} 2$ discharges (in Kilogram) and vitality utilization (in MiliJoule) per ton of concrete.

- System Boundary

- Inventory Analysis

- Impact Assessment

- Comparative Analysis

\section{$>$ Characterization of Raw Material}

For the main arrangement of tests, materials recorded beneath in Table were secured from various areas. These materials were chosen based on their compound properties. If there should arise an occurrence of calcined earth, high responsive great quality mud, and a medium receptive mud (80 to $85 \%$ calcined) was chosen. Slag utilized for creation of Portland slag concrete was chosen from nearby . One fly debris was gathered from warm force plant situated close to Rajasthan .Unadulterated limestone was secured in crude state and was squashed in a lab ball factory. In the wake of pounding, squashed limestone was sieved through 80-100 micron sifter. One kind of mechanical evaluation quartz with high fineness was chosen.

All materials were tried for physical, substance and morphological properties as appeared underneath tables and figure. For molecule size dispersion, wet sifter investigation was performed with 90 and 45-micron strainer. Explicit gravity of every material was estimated with the assistance of Le-Chatlier jar.

\section{Preparation of Blends from SCMs:}

For mixes of SCMs, SCMs were mixed in a ball plant with greatest limit of 20 kilogram. During the mixing, proportion of balls and material was $1: 1$, and greatest size of balls was $10 \mathrm{~mm}$. Ball plant was turned for 25-35 minutes for each mix. 
ISSN No:-2456-2165

\begin{tabular}{|c|c|c|c|c|c|c|c|}
\hline \multicolumn{2}{|c|}{ Physical Properties } & Clay 1 & Clay 2 & Lime stone & Fly Ash & Slag & Quartz \\
\hline \multicolumn{2}{|c|}{ Specific Gravity } & 2.7 & 2.67 & 2.67 & 2.26 & 2.88 & 2.65 \\
\hline \multirow{2}{*}{$\begin{array}{c}\text { Sieve analysis } \\
\text { retained weight }\end{array}$} & $90 \mathrm{~m}$ & 0.10 & --- & 1.95 & 9.30 & 0.00 & 0.05 \\
\cline { 2 - 8 } & $45 \mathrm{~m}$ & 0.09 & --- & 15.48 & 20.69 & 1.36 & 0.68 \\
\hline
\end{tabular}

Table 2:- Physical Properties of Different SCMs

\begin{tabular}{|c|c|c|c|c|c|c|c|}
\hline No. & Constituent \% & Clay 1 & Clay 2 & Lime stone & Slag & Quartz & Gypsum \\
\hline 1 & Loss on ignition & 8.24 & 10.28 & 36.96 & 0.32 & 1.08 & 23.02 \\
\hline 2 & ${\mathrm{Silica} \mathrm{SiO}_{2}}$ & 51.60 & 54.67 & 11.02 & 32.26 & 93.30 & 2.77 \\
\hline 3 & Iron $\mathrm{Fe}_{2} \mathrm{O}_{3}$ & 1.15 & 4.93 & 1.55 & 1.93 & 0.63 & 0.36 \\
\hline 4 & Aluminium $\mathrm{Al}_{2} \mathrm{O}_{3}$ & 36.13 & 27.69 & 2.53 & 23.16 & 1.83 & 0.62 \\
\hline 5 & Calcium $\mathrm{CaO}$ & 0.54 & 0.06 & 44.24 & 33.88 & 0.56 & 32.62 \\
\hline 6 & Magnesium $\mathrm{MgO}$ & 0.77 & 0.13 & 1.96 & 7.01 & 0.80 & 1.20 \\
\hline 7 & Sulphate $\mathrm{SO}_{3}$ & --- & 0.01 & -- & Traces & Traces & 38.75 \\
\hline 8 & Sodium $\mathrm{Na}_{2} \mathrm{O}$ & 0.10 & 0.12 & 0.50 & 0.34 & 0.93 & 0.06 \\
\hline 9 & Potassium $\mathrm{K}_{2} \mathrm{O}$ & 0.04 & 0.25 & 0.28 & 0.65 & 0.37 & 0.037 \\
\hline 10 & Combined $\mathrm{Water}_{2}$ & --- & --- & --- & --- & --- & 16.30 \\
\hline 11 & Reactive $\mathrm{Silica}_{(\mathrm{SiO}}$ ( & --- & --- & --- & 31.58 & 3.12 & --- \\
\hline 12 & Manganese $\mathrm{Mn}_{2} \mathrm{O}_{3}$ & --- & 0.01 & --- & 0.30 & --- & --- \\
\hline
\end{tabular}

Table 3:- Chemical properties of different SCMs

\begin{tabular}{|c|c|c|c|}
\hline Blends & SCM 1 & SCM 2 & Ratio \\
\hline B1 & Clay 1 (20m Clay) & Limestone 1 & $2: 1$ \\
\hline B2 & Clay 1 (20m Clay) & Limestone 1 & $1: 1$ \\
\hline B3 & Clay 1 (20m Clay) & Limestone 1 & $1: 2$ \\
\hline B5 & Clay 1 (20m Clay) & Dolomite & $2: 1$ \\
\hline B6 & Clay 2 (Bhuj Clay) & Limestone 1 & $2: 1$ \\
\hline B8 & Clay 1 (20m Clay) & Quartz & $2: 1$ \\
\hline B9 & Quartz & Limestone 1 & $2: 1$ \\
\hline B10 & Fly ash 1 & Slag & $1: 2$ \\
\hline B11 & Fly ash 1 & Slag & $1: 1$ \\
\hline B12 & Fly ash 1 & Slag & $2: 1$ \\
\hline
\end{tabular}

Table 4:- Blends of SCMs

After planning of mixes, Calorimetry and Lime reactivity according to IS 1727-1967 and a recently evolved strategy was performed on SCMs and their mixes.

\section{A. Calorimetry}

This test was performed to gauge all out warmth developed in the hydration response of SCMs and $\mathrm{CH}$ within the sight of water at $25^{\circ} \mathrm{C}-28^{\circ} \mathrm{C}$. For quickening the responses, pore arrangement was likewise attempted. To get ready pore arrangements, concrete was mixed with water for various term and afterward sifted water was utilized as pore arrangement. It tends to be plainly seen from Figure 2, that pore arrangement quickens the response however with little varieties.

Calorimetry was likewise performed on mixes of SCMs with same system. Calorimetry helps in two different ways for the investigation of mixed SCMs. One, it tells about the absolute warmth advanced which can be because of the response of SCMs with one another. What's more, second, it tends to be utilized to adjust the best possible mixing of two distinct materials. Sample which contains quartz and limestone demonstrated no responses till the age of 7 days. Rest of the mixes is by all accounts alright according to the underlying investigation.

\section{B. Lime Reactivity (IS 1727-1967)}

This test was acted as per Indian Standard 1727-1967. Mortar was set up according to the strategy in the norm. As a matter of first importance, trails for suitable water powder proportion overlooking wanted functionality were performed. The water rate at long last used to plan mortar is given in Table 3. It is obvious from functionality test that earth 1 and mud 2 was the most noteworthy water requesting SCMs. Earth 1 was similarly better then Clay 2. After preliminaries, mortar 3D squares of $50 \times 50 \times 50 \mathrm{~mm}$ size were casted and put away in the lab conditions for initial 48 hours. During this period, molds were secured with glass plate to stay away from any vanishing misfortunes. Following 48 hours, solid shapes were de formed and afterward positioned in plate. 3D shapes were secured with a wet bit of material from all the sides and afterward put away in stickiness chamber at $50^{\circ} \pm 2$ Cand 90\% relative dampness. Following 10 days from projecting, 
examples were tried for compressive quality under a pressure testing machine of limit 50KiloNewton.

\begin{tabular}{|c|c|c|c|c|c|c|c|c|}
\hline Mix & Quartz & Slag & Clay2 & Clay1 & S1 & S2 & S3 & S4 \\
\hline $\begin{array}{c}\text { Water } \\
\%\end{array}$ & 23 & 17 & 21.5 & 28 & 23 & 20 & 19 & 16 \\
\hline
\end{tabular}

Table 5:- Water demand for workability trials
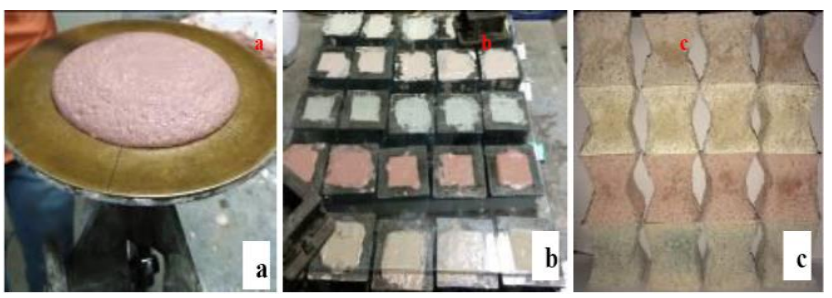

Fig 1:- Workability test trail

\section{Material Used in the Study}

- Cement - Ordinary 53 grade Portland cement

- Limestone Calcined Clay Cement - 55\% clinker, 30\% calcined clay and $15 \%$ limestone

- FA30 - Ordinary Portland cement 70\% + 30\% ASTM Class F

- Superplasticizer - PCE (commercial name: Master Glenium Sky 8233, Solid content 34\%)

Test conducted :

The flow conduct of concrete is described by basic observational techniques, for example, Marsh cone test and smaller than normal droop test. Rheological investigations are additionally led to comprehend the major data about the material. The methodology embraced in these test strategies are itemized beneath:

\section{> Mini-Slump Test}

The smaller than usual droop is a form looking like a shortened cone with measurements corresponding to the Abram's cone. The technique and trial arrangement for smaller than expected droop cone are given underneath The form is put on a spotless glass sheet of reasonable measurements. The form is then loaded up with concrete glue. In the wake of filling, the form is lifted up vertically and the concrete glue is permitted to spread unreservedly. The distance across of the concrete glue is estimated in two ways symmetrically subsequent to lifting the shape and the normal worth is communicated as the spread of the concrete glue. Moreover, the time taken for the glue to arrive at a distance across of $115 \mathrm{~mm}$ is resolved. Additionally, visual assessment assists with assessing the draining and isolation of the glue.
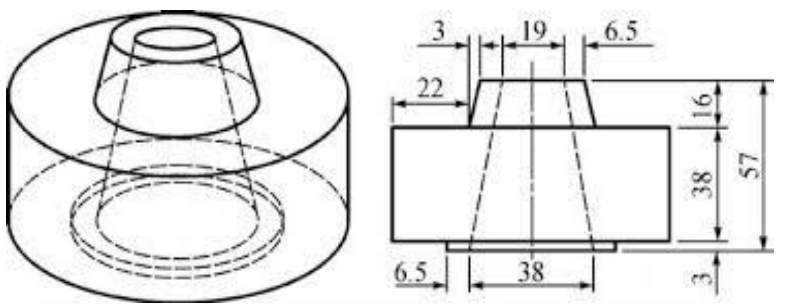

Fig 2:- Schematic diagram of mini-slump test cone geometry

\section{Marsh cone test}

The Marsh cone test is utilized to assess the relative ease and immersion superplasticizer measurement in concrete glue and mortars. In the current examination, a metal cone (according to the rules of European principles EN445, French norms P 18-358,which is simialr to ASTM C939 (1987), with a spout width of $8 \mathrm{~mm}$ is utilized.

$>\quad$ An fundamental volume of $1000 \mathrm{ml}$ stick was filled the cone and the time required for $500 \mathrm{ml}$ of it to stream out was evaluated. The test gives the perfection of paste the extent that stream time higher the stream time, lower is the simplicity.

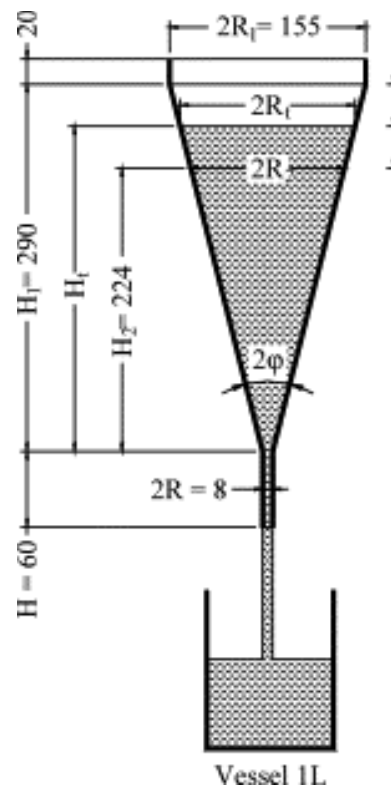

5 Free surface at initial moment $\mathrm{t}=0$ Free surface at the actual moment $t>0$ Free surface at the final moment (volume leaving equal to $1 \mathrm{~L}$ )

$R, H \quad$ Radius and length of the ajutage

$R_{3}, H_{l} \quad$ Radius of the free surface and height of the fluid in the truncated cone at the initial moment $\mathrm{t}=0$

$R_{6}, H_{t} \quad$ Radius of the free surface and height of the fluid in the truncated cone at the actual moment $t>0$

$R_{2} H_{2}$ Radius of the free surface and height of the fluid in the truncated cone at the final moment

$\varphi \quad$ Angle between the generatrices and the axis of the truncated cone

Fig 3:- Geometry and dimension of Marsh cone test

The immersion point is the measurement past which further expansion of superplasticizer doesn't expand ease altogether yet can create isolation (Agullo et al., 1999); the immersion dose can be taken as the ideal superplasticizer dose for a given concrete glue.

\section{$>$ Determination of Initial and Final Setting times}

The underlying and last setting occasions are resolved according to IS 4031: Part 5 (2005). The concrete glue is set up with same water required to give a glue of standard consistency. It is filled in the Vicat mould and the comparing needle is permitted to infiltrate through the glue. The period slipping by between when water is first added to the concrete and the time at which the infiltration of the needle is $35.0 \pm 0.5 \mathrm{~mm}$ is taken as the underlying setting time. Note this is like system of ASTM C-191 (2001a), then again, actually the glue utilized (i.e., same w/c) is of standard/typical consistency, and the entrance for the underlying setting time is $25 \mathrm{~mm}$. 
The test is proceeded with a standard needle with an annular connection for deciding the last setting time. The period slipping by between when water is added to the concrete and the time at which the needle establishes a connection with the outside of the test square while the connection neglects to do so is taken as the last setting time.

\section{$>$ Carbonation}

In LC3 frameworks there is an early age utilization of calcium hydroxide for a quick quality addition due to pozzolanic movement. That prompts the decrease in general $\mathrm{pH}$ just as lesser accessibility of carbon table material in the general framework. So there will be an expanded pace of development of carbonation front in the framework. This may prompt the decrease of timeframe for the carbonation front to arrive at the steel layer in strengthened cement. In this way, there will be a higher chance erosion commencement at much early age in LC3 frameworks on the off chance that it is seen appropriately. To have a superior comprehension are being directed and correlations made against the OPC and PPC blends.

Solid examples were projected with two diverse water to solidify proportion, from that point the examples were relieved for 120 days.Compressive quality of cement was estimated utilizing 3D shape examples having measurement of $15^{*} 15^{*} 15 \mathrm{~cm} 3$ at 28 and 120 days. Subsequent to restoring, solid examples were molded at $27^{\circ} \mathrm{C}$ and $65 \%$ relative dampness for 15 days. Adapted examples were uncovered in regular habitat.

To gauge the carbonation profundity solid light emissions $50 * 10 * 10 \mathrm{~cm} 3$ were projected and a piece of it was cut utilizing paver shaper hinder at different ages to decide the carbonation profundity by splashing phenolphthalein marker on the cut segment.

Water ingestion test was led according to ASTM C642-06 to decide change in volume of solid example relying on degree of carbonation. An estimation of slim porosity in concrete wasobtained by deciding sorptivity because of narrow ascent assimilation rate. The test was directed as per ASTM C1585-13. Powder tests were penetrated from solid example at various age to discover change happen in $\mathrm{pH}$, save alkalinity and change in hydration items on account of carbonation

\section{Corrosion}

Corrosion of steel in reinforced concrete structures is one of the major deteriorating mechanisms leading to failure. Corrosion of steel-cementitious systems is mainly of two types namely (1) Chloride induced corrosion and (2) Carbonation induced corrosion. Cementitious systems play a major role in preventing the ingress of degenerating agents in the form of low permeability, low penetrability (high resistivity) and chloride binding. The use of pozzolanic material in concrete is widely practiced to delay the onset of corrosion and slower the corrosion rate. LC3 is one of the promising cementitious systems with high resistivity and low permeability. This study is concerned with the corrosion performance of steel in LC3 systems w.r.t. chloride ions. The study is categorized based on the exposure time as short term testing and long term testing. Impressed Current Corrosion (ICC) Test and Wet-Dry Corrosion (WDC) test with premixed chlorides are included in short term testing. Long term performance is assessed by ASTM G109 standard test method

\section{RESULTS AND CONCLUSION}

\section{Strength of cements}

Mortar solid shapes of $706 \mathrm{~mm}$ size have been set up with Limestone Calcined Clay Cement and OPC utilizing standard sand keeping concrete to sand proportion as 1:3 with distinctive water to solidify proportion. Compressive qualitie of the mortars $3 \mathrm{D}$ shapes at 3, 7, 28, and 56 days were estimated and appeared .

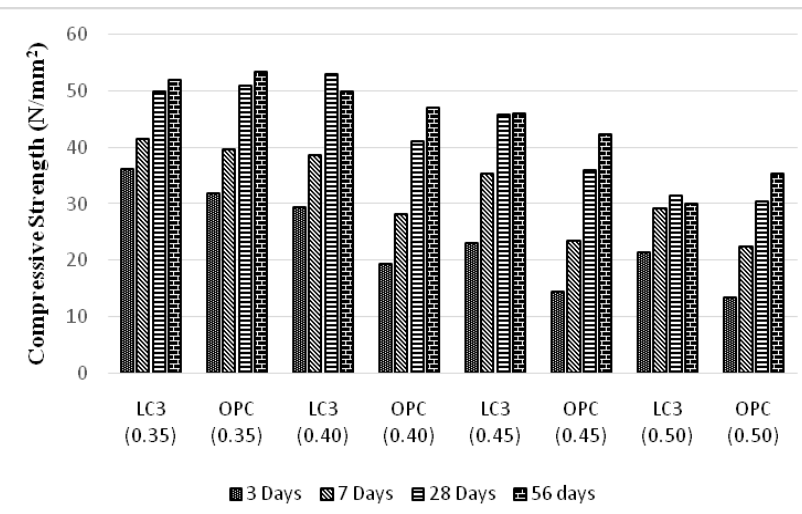

Fig 4:- Mortar strength results of Limestone Calcined Clay Cement and OPC

\section{Compressive Strength}

Limestone Calcined Clay Cement concrete with two folio substance of $310 \mathrm{~kg} / \mathrm{m} 3$ and $340 \mathrm{~kg} / \mathrm{m} 3$ and water concrete proportions from 0.40 to 0.60 were set up to finish the structures forM30 and M50 grade concrete. To get the evaluation of cement and to fix the ideal measurements of superplasticizers, preliminary blends were accomplished for the distinctive cover substance and water to solidify proportions and tried for the shape compressive quality at 2 , 7 and 28 days of relieving. After the preliminary blends, huge clusters were blended for the mechanical, sturdiness and erosion property examines respectively.

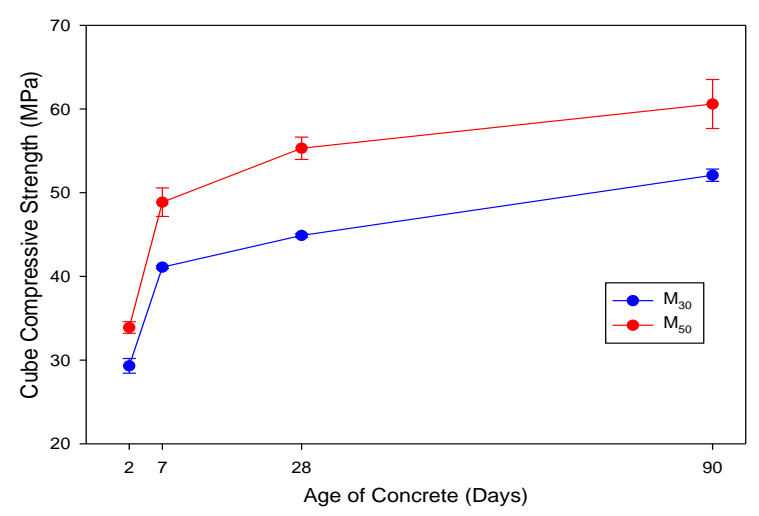

Fig 5:- Compressive strength vs Age 
In view of the preliminary blends, the water to solidify proportion and the concrete substance for M30 and M50 grade concrete were fixed as $0.50 ; 310 \mathrm{~kg} / \mathrm{m} 3$ and 0.40 ; $360 \mathrm{~kg} / \mathrm{m} 3$ separately.

\section{Shrinkage and cracking}

In the wake of demolding, the examples were kept in a damp space for relieving $(\mathrm{RH}=95 \pm 5 \%)$. Growing and shrinkage of cement was observed utilizing $75 \times 75 \times 285$ $\mathrm{mm}$ crystal examples. The readings were taken day by day during the relieving time of 28 days. Figure 12.2 shows the development patterns of M30 and M50. The blend M30 gave a normal expanding of 20 smaller scale strains, though M50 blends shows a higher growing of around 40 miniaturized scale strain, potentially on the grounds that it contains higher concrete and lower water content in the blend. All things considered, the two qualities are insignificant for commonsense purposes. Change number of segments

After the relieving time frame (28 days), the examples were moved to a controlled domain for shrinkage testing (kept up at temperature $-25^{\circ} \mathrm{C}$ and relative stickiness -65 $\%)$. Subsequent to molding, three examples were wrapped with aluminum foil tape for checking autogenous shrinkage and three examples were fixed distinctly at the closures for all out shrinkage estimations. Autogenous shrinkage was in the scope of 50 to 60 microstrain for both the blends. Note that the estimations of autogeneous shrinkage revealed here is just that which happened following 28 days, and does exclude the significant piece of autogenous shrinkage that happens during hydration; these qualities are just implied as the reference for the deciding the drying shrinkage esteems. The all out shrinkages for M30 and M50 blends were in the scope of 160 and 200 microstrain, separately, following 120 days of drying.

\section{REFERENCES}

[1]. Concrete for the Environment. Published on behalf of the Nordic network concrete for environment by SP Swedish national testing and research institute. Boras, June 2003.

[2]. Frederick S. Merritt Jonathan T. Ricketts - Building design and construction hand book\| McGraw hill, six editions, 2001.

[3]. A Practical Guide to Microstructural Analysis of Cementitious Materials, https://www.crcpress.com/APractical-Guide-to-Microstructural-AnalysisofCementitious-Materials/Scrivener-SnellingsLothenbach/p/book/9781498738651 Scrivener Karen 2016.

[4]. Su.PILLA, devadasi MENON "reinforced concrete design\| McGraw hill, second edition, 2003.

[5]. Madan MEHTA, Walter SCARBOROUGH and Diane ARMPRIEST "building construction principle, materials and system\|, prentice hall, second edition, 2013.
[6]. Development of a new Rapid Relevant and Reliable to evaluate the pozzolanic potential of calcined kaolinitic clays-Cement and Concrete Research 85 (2016) 1-11

[7]. www.researchgate.net/publication/281698370_Econo mic_Implications_of_Limestone_C linker_Calcined_Clay_Cement_LC3_in_India.

[8]. Pilot scale manufacture of limestone calcined clay cement; The Indian experience www.lc3.ch

[9]. 1st International Conference on Calcined Clays for Sustainable Concrete, June 2015, Lausanne, Switzerland Editors: K Scrivener, Aurelian Favier. 